\title{
The Latest Unique Achievements in Science on Water
}

\author{
V. V. Goncharuk* \\ Dumanskii Institute of Colloid Chemistry and the Chemistry of Water, \\ National Academy of Sciences of Ukraine, Kiev \\ *e-mail: honch@iccwc.kiev.ua \\ Received February 10, 2015
}

DOI: $10.3103 / \mathrm{S} 1063455 \mathrm{X} 15010014$

The journal Chemistry and Technology of Water in 2015 opened a new heading The New in Science about Water, which is based on a series of outstanding latest results obtained in investigating properties, the structure of water, its fundamental role in the origin of life on Earth. In particular the team of scientist of the Dumanskii Institute of Colloid Chemistry and the Chemistry of Water, National Academy of Sciences of Ukraine, jointly with foreign scientists in recent years have obtained unique results in science about water:

- A new hypothesis about genesis of hydrosphere has been put forward. It has been shown that the natural background of neutrons is not enough for enrichment of the hydrosphere with deuterium. Enrichment of the matter of the protoplanetary cloud with deuterium and perhaps, lithium, beryllium and boron promoted the formation of the earthly group of planets in the Solar system;

- It has been shown that the origin of life on Earth and in space is determined by the presence of water and carbon dioxide, which are main precursors of organic matter on Earth and other objects of the space. A conclusion was made that main ingredients necessary for life may exist both in the Solar system and the galaxy.

- Unique results were obtained on isotope osmosis of water with a different content of deuterium; in light, heavy and usual waters. It has been sown that isotope osmosis through a semipermeable polymer membrane suppresses the osmosis current existing due to different concentrations of chemical components in light and heavy waters.

- The logic in the formation of porous ice has been investigated. Experimental data on the water freezeup and formation of cylindrical and spherical gas inclusions appearing in ice when the water is cooled being in equilibrium with the atmosphere had been obtained. Theoretical models describing the change of the water aggregate state, gas concentration and formation of porous ice have been proposed.

- Based on the phylogenetic analysis using methods of molecular biology on sequences of the 16S pPHK gene a number of bacteria species were identified in chlorinated drinking water. Investigated strains belong to the phylum Firmicutes of the class Bacilli. The presence of studied bacteria in chlorinated drinking water given such stress factors as high or low temperatures, presence of disinfectants is an evidence of their adaptability to new conditions of existence extending the range of habitat.

- New State standards for drinking water have been approved: GSTU 7525:2014 Drinking Water. Requirements and Method of Determination of Cyto- and genotoxicity of water in aqueous solutions on blood cells of fresh-water fish Danio rerio (Hamilton-buchanan); GSTU 7487:2013 Water Quality. Method of Determination of Micromycetes without analogues in the water. The method of determination of cyto- and genotoxicity on blood cells of freshwater fish as test objects is based on determination of the blood formula and the amount of morphological changes of nuclei of erythrocytes in peripheral blood of fish. It provides an integral assessment of summary action of all toxicants with the account of their synergism and antagonism. Standards extend over natural, drinking and bottled waters and establish requirements to determination of biological, chemical and radiochemical toxicants in water.

- New methods of producing and modification of micro- and ultrafiltration ceramic membranes based on clayey minerals have been developed. It has been found that for the production of the most effective microfiltration ceramic membranes it is necessary to use the most highly disperse fractions of clayey minerals. Ultrafiltration ceramic membranes it is expedient to produce modifying microfiltration ceramic membrane by sols of metal oxides. 